\title{
Hybrid natural and glass fibers reinforced polymer composites material selection using Analytical Hierarchy Process for automotive brake lever design.
}

\begin{abstract}
Due to recent trend and increasing awareness towards sustainable product design, natural based fiber materials are gaining a revival popularity to replace synthetic based fiber in the formulation of composites especially for automotive structural and semi structural applications. In this paper, the Analytical Hierarchy Process (AHP) method was utilized in the selection of the most suitable natural fiber to be hybridized with glass fiber reinforced polymer composites for the design of a passenger vehicle center lever parking brake component. Thirteen (13) candidate natural based fiber materials for the hybridization process were selected and analyzed to determine their overall scores in three (3) main performance indices according to the component product design specifications. Using the AHP method, the kenaf bast fiber yields the highest scores and was selected as the best candidate material to formulate the hybrid polymer composites for the automotive component construction. Sensitivity analysis was also performed and results show that kenaf bast fiber emerged as the best candidate material in two out of three simulated scenarios, which further validates the results gained through the AHP method.
\end{abstract}

Keyword: Hybrid polymer composites; Product design specifications; Material selection; Analytical Hierarchy Process; Automotive component design 